\title{
Development of Emissions Inventory and Pollution Classification for Energy- Intensive Heavy Metal Industries in A Densely Distributed Area
}

\author{
Jia Jia*, Jingjing Yang**†, Yawen Song***, Huimin Chen**** and Xi Zhang**** \\ *School of Management Engineering, Zhengzhou University of Aeronautics, Zhengzhou 450046, China \\ **Information Management Department, Zhengzhou University of Aeronautics, Zhengzhou 450046, China \\ ***School of Foreign Languages, Zhengzhou University of Aeronautics, Zhengzhou 450046, China \\ ****Henan Tianlang Ecological Technology Co. Ltd., Zhengzhou 450046, China \\ $\dagger$ Corresponding author: Jingjing Yang; jasper@zua.edu.cn
}

Nat. Env. \& Poll. Tech.

Website: www.neptjournal.com

Received: 02-03-2020

Revised: $05-06-2020$

Accepted: $10-12-2020$

Key Words:

Iron and steel industry

Air pollutants

Negative health impact

CAMx

Classification technology

\begin{abstract}
The iron and steel industry puts considerable pressure on the regional environment of the BeijingTianjin-Hebei $(\mathrm{BTH})$ area, and the $\mathrm{PM}_{2.5}$ pollution has caused serious harm to public health. To explore a detailed and high-resolution emission inventory of the iron and steel industry in the BTH region, a classification technology method with CAMx modelling system was developed and applied for classifying all the iron and steel enterprises in the BTH region. Besides, simulation scenarios were designed particularly for quantitatively assessing the effectiveness of the environmental protection measures. Results show that the pollutant emission of the iron and steel industry significantly contributes to the $\mathrm{PM}_{2.5}, \mathrm{SO}_{4}^{2-}, \mathrm{NO}_{3}^{-}$, and $\mathrm{SOA}$ concentrations in the atmospheric environment in sub-areas. Therefore, the enterprises in western and central sub-areas show high classification coefficients. Restricting pollutant emissions using the developed classification technology method is more effective in reducing the $\mathrm{PM}_{2.5}$ concentration of the $\mathrm{BTH}$ region compared with the proportional reduction method. Thus, the classification method should be primarily implemented for reducing the air pollutant emissions of the iron and steel industry in the BTH region.
\end{abstract}

\section{INTRODUCTION}

The iron and steel industry, which has rapidly grown along with the increasing demand derived from the rapid urbanization and various infrastructure construction activities, plays an important role in the development of China. However, the iron and steel industry has become one of the highest energy consumption and pollutant emission industries due to its rapid economic expansion (Tao et al. 2014). Enormous quantities of air pollutants were generated (Huang et al. 2014, Yang et al. 2017, Chen et al. 2014, Sina et al. 2019), resulting in significant regional environmental problems (Amodio et al. 2013). The Beijing-Tianjin-Hebei (BTH) region, wherein numerous iron and steel enterprises are gathered and the steel production capacity accounts for approximately one-third of China according to the report of the Ministry of Industry and Information Technology, has trapped itself in a dilemma known as the "Steel Overcapacity" (Li et al. 2017), which puts considerable pressure on the regional environment. Moreover, the iron and steel industry has been progressively recognized to have a strong impact on human health, thereby increasing mortality and morbidity rates due to respiratory diseases.
The iron and steel industry is identified as an energy and pollution-intensive manufacturing sector (Wang et al. 2016) and an important emission source of air pollutants ( $\mathrm{Li}$ et al. 2016). Therefore, a systematic and reliable estimation of its emissions is essential for policymakers to address critical atmospheric environmental hazards. In most studies, the emission inventories of air pollutants treated the iron and steel industry as a whole in the industrial process emissions mainly due to data availability (Streets et al. 2003, Cheng et al. 2012, Zhou et al. 2014). High-resolution emission inventories of primary air pollutant emissions in the Pearl River Delta (PRD) region and the Yunnan and Hebei Provinces in China were built (Zheng et al. 2009, Tang et al. 2012, Zhao et al. 2012) based on the data from the statistical yearbooks. However, these studies revealed that the iron and steel industry was still treated as one of the large industrial point sources. Inventories of different industries were created to understand the operational process and pollutant emission characteristics effectively. Wu et al. (2015) estimated the direct emissions of air pollutants from the iron and steel industry. Wang et al. (Wang et al. 2016) built a comprehensive emission inventory for the iron and steel industry in China with multiple air pollutants. A comprehensive and 
high-resolution atmospheric emission inventory of multiple air pollutants from the iron and steel industry in the BTH region, covering almost all the iron and steel plants and processes (coking, sintering, puddling, steelmaking and rolling), is developed in this study to examine the pollution characteristics and the negative effects on the atmospheric environment.

Identifying the most important pollution sources based on emission inventories is crucial for the development of effective emission control strategies. The comprehensive air quality model with extensions (CAMx) model, which could simulate the emission, dispersion, chemical reaction, and removal of pollutants by marching the Eulerian continuity equation forward in time for each chemical species, was developed (Pateraki et al. 2013, Bossioli et al. 2013). Guttikunda et al. (2014) applied the CAMx model to estimate the pollution contribution for individual coal-fired thermal power plants in India and advised that aggressive pollution control regulations are imperative for regional clean air. The CAMx model was also applied in the BTH region by $\mathrm{Li}$ et al. (2015) for comparing the pollution contribution between anthropogenic emissions and exploring the quantitative understanding of the source receptor relationships. The CAMx model was employed in this study to simulate the sensitivity of iron and steel enterprises to various pollutants, and the results were used for assessing and classifying the emission sources.

As an extension of previous efforts, this study provides a detailed and high-resolution emission inventory of the iron and steel industry in the BTH region and employs the CAMx modelling system to simulate the sensitivity of enterprises to various pollutants. A classification technology method is developed based on the emission inventory and simulation results. This method is used for assessing the influence of pollution emission from sources on $\mathrm{PM}_{2.5}$ concentration and classifying the iron and steel enterprises in the BTH region. Multiple scenarios are also assumed and simulated to analyze the influence of reducing pollutant emissions of the iron and steel industry. The BTH region is probably the most important gathering centre of the iron and steel industries in China. Thus, this study provides a rare and valuable opportunity for examining the impact of pollutant emissions from iron and steel enterprises on air pollution. The results would also provide a scientific base for governments in China to make sound control policies and measures in the future, which aim to provide a clean air environment for people to reduce the negative impact of air pollution on human health.

\section{MATERIALS AND METHODS}

The emissions of air pollutants $\left(\mathrm{SO}_{2}, \mathrm{NO}_{\mathrm{x}}, \mathrm{CO}\right.$ and VOCs), $\mathrm{PM}_{2.5}$ (particles with an aerodynamic diameter of $2.5 \mu \mathrm{m}$ ), and total suspended particulate (TSP) from the iron and steel industry in the BTH region in 2015 are estimated in this study by applying a unit-based and bottom-up methodology with a refined activity database. Varied processes are sub-grouped and separately considered in this methodology in terms of different patterns of process facilities and pollution control measures. Fig. 1 shows the geographical locations of the iron and steel enterprises in the BTH region.

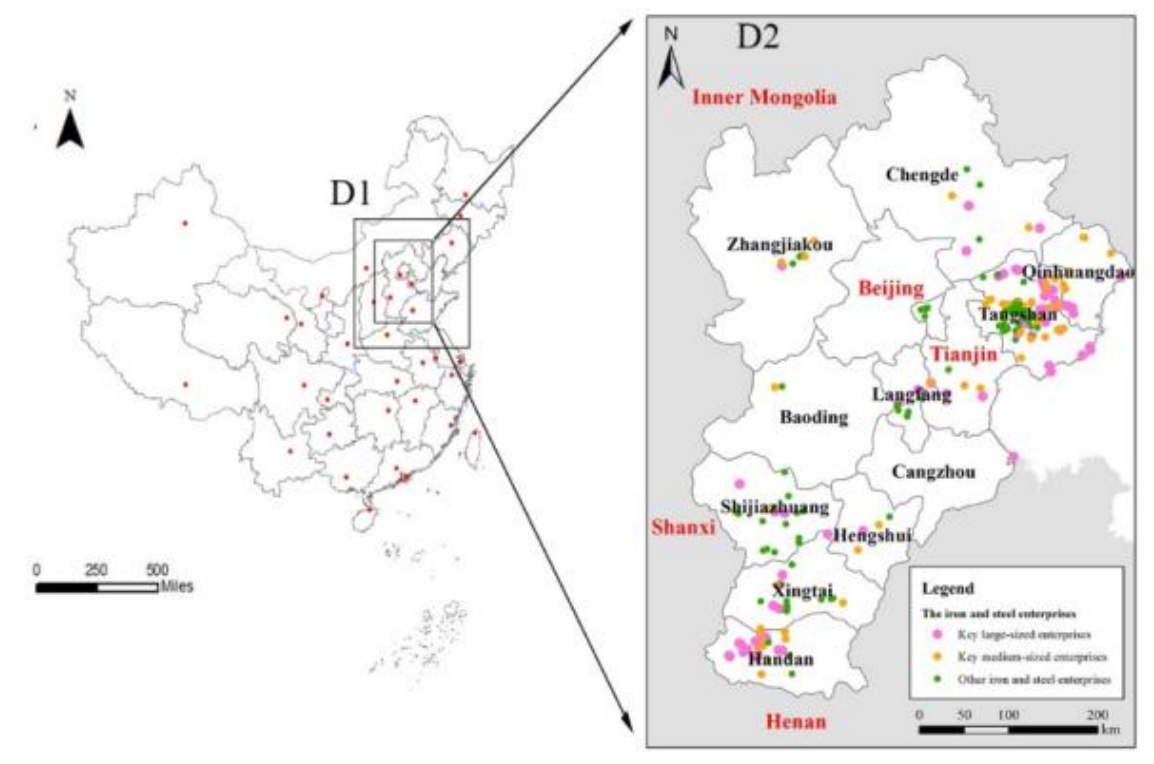

Fig. 1: Geographical locations of the iron and steel enterprises in the BTH region and the double nesting simulation domain of the CAMx model. 


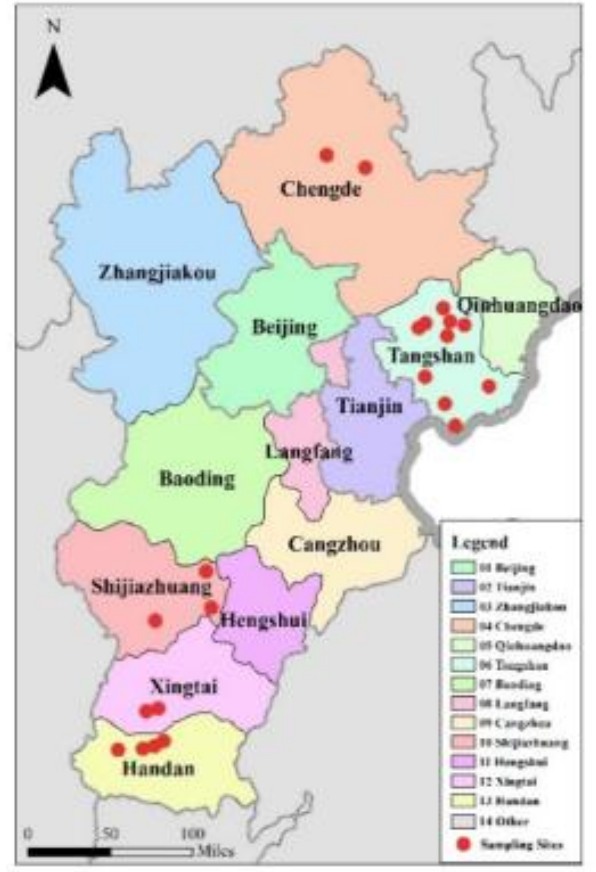

Fig. 2: Localization of the sampled iron and steel enterprises and the 14 sub-areas delineated as the pollution source inputs for the CAMx model.

\section{Sampling Sites Description}

In recent years, approximately 20 iron and steel enterprises in the BTH region and their air pollutant emission outlets were sampled and monitored by the members of the Key Laboratory of Beijing on Regional Air Pollution Control. The enterprises were selected based on the production process, pollution control facilities and geographical location. All the traditional iron and steel production processes were involved, and various kinds of pollution control facilities, including wet and semi-dry flue gas desulfurization facilities, bag filter facilities and electrostatic precipitator facilities, were also involved. Fig. 2 presents the localization of the sampled iron and steel enterprises.

The concentrations of $\mathrm{SO}_{2}$ and $\mathrm{NO}_{\mathrm{x}}$ were collected from the on-line monitoring device, which was widely popularized in the iron and steel enterprises in the BTH region. PM and VOC samples were respectively collected by filters and summa canisters by dilution sampling systems (Wang et al. 2016, Wei et al. 2014). The inductively coupled plasma mass spectrometry (ICP-MS, 7500a, Thermo), ion chromatography (IC, Metrohm 861 Advanced Compact IC), and thermal/optical carbon analyser (DRI Model 2001A, Desert Research Institute of United States) were used not only for determining the concentration of $\mathrm{PM}_{2.5}$ and TSP from the well-stored samples collected from the air pollutant outlets under real conditions (Wang et al. 2015) but also for testing the concentration of elements, water-soluble ions, and carbonaceous species, respectively. In addition, the VOC samples were measured by using gas chromatography-mass spectrometry (GC-MS, Model 7890A/5975C, Agilent Inc). Details of the sampling process, sample analysis, and quality control could be found in previous works published by the researchers of the Key Laboratory of Beijing on Regional Air Pollution Control (Wei et al. 2014, Li et al. 2014, Wei et al. 2016).

\section{Emission Inventory and Uncertainty Analysis}

The emission inventory of the iron and steel industry is calculated on the basis of the detailed activity data collected from investigation and source-specific emission factors $(E F)$ to determine the emission characteristics of the gaseous pollutants and PM in iron and steel enterprises. This calculation is shown in Eq. (1).

$$
E=E F \times A L
$$

Where $E$ is the emission estimate for a source category, $E F$ is the emission factor for the category, and $A L$ is the collected activity data. Emission factors, rather than pollutants producing factors, are chosen for calculation in this study mainly because of the uneven and discrepant control measures and efficiencies in iron and steel enterprises in the BTH region. A bottom-up approach was used for developing the emission inventory for all iron and steel enterprises in the BTH region.

Previous works published by the researchers of the Key Laboratory of Beijing on Regional Air Pollution Control provide the emission inventories of other industries (e.g., power plants, chemical processing enterprises, and architectural material industry) and non-industrial sectors (e.g., pollutants from residential areas, dust from vehicles, roads, and construction sites) used in this study.

The iron and steel industry involves a series of interrelated processes. Considering the most recent study, the iron and steel industry inventory developed in this study includes the following main source categories. (1) Coking process, in which coals are carbonized to generate the coke. (2) Sintering process (including sintering and pelletizing sub-categories), in which raw materials comprising fine iron ores and flux materials are agglomerated by combustion to produce sinter products. This process involves two sub-categories: sintering and shaft furnace (pelletizing). (3) Puddling process, in which sinter and coke products are subsequently introduced in the blast furnace to generate pig iron. (4) Steelmaking process, in which molten iron is combined with scrap steels and fluxes and transported to furnaces to produce molten steel. This process includes the following sub-categories: basic oxygen furnace (BOF) and electric arc furnace (EAF). (5) Rolling process, in which molten steel is solidified to produce the final iron and 
steel products. The sub-categories of this process include hot and cold rolling. (6) Unorganized, which particularly focuses on $\mathrm{PM}_{2.5}$ and TSP emissions for each process.

The resolution of activity data determines the preliminary resolution of emission inventory. A complete investigation of activity data was launched for all iron and steel enterprises of the BTH region to obtain detailed data for establishing a highresolution emission inventory. Detailed statistic information was obtained with the assistance of provincial and municipal environmental protection bureaus and administration departments. The activity data contain the production of coke, sinter, pig iron, and crude and rolled steels, which were used for calculating the emission from each process of iron and steel enterprises, and the unorganized emission. Other data, including the removal efficiency of control facilities, operating expense, and economic cost, were also collected directly.

The emission factors in this study were acquired from three ways. (1) Sampling results, in which the emission factors were calculated on the basis of concentrations of gaseous pollutants and PM and the manufacture of products for each source category; (2) The Manual of Emission Coefficient; (3) existing studies, that is, the average emission factors of $\mathrm{CO}$ for varied process steps by referring to available research results and simultaneously considering comparable pollution control facilities (Streets et al. 2006). Essentially, the emission factors applied for developing the iron and steel inventory were acquired from the sampling results and existing studies (mainly for emission factors of $\mathrm{CO}$ ). Meanwhile, the emission factors acquired from the Manual of Emission Coefficient and existing studies were also used for verification and comparison with the emission factors from sampling results. Table A1 lists the emission factors applied for calculating the emission inventory of the iron and steel industry in the BTH region and the comparison between emission factors from different ways.

Overall, the emission factors captured from the sampling results were slightly lower than those of previous studies. This finding is mainly attributed to the significant improvement of the pollution control technology in the iron and steel industry over the past few years and the increase in the popularization rate of pollutant control facilities. However, part of the $\mathrm{NO}_{\mathrm{x}}$ emission factors in the sintering process and the PM emission factors in the steelmaking process showed adverse tendencies compared with others. This result is associated with the operation of only a few $\mathrm{NO}_{\mathrm{x}}$ removal equipment (Wu et al. 2015) in the BTH region and the lower efficiency of the existing pollution control facilities than expected.

\section{Modelling System}

The CAMx model was employed in this study to simulate the impact of pollutant emissions of iron and steel enterprises on the atmospheric environment, and the simulation results were used for assessing and classifying the emission sources. The Weather Research \& Forecasting (WRF) model was used for simulating the meteorological background for air quality simulation. Particulate Source Appointment Technology (PSAT) was used in the simulating process as a source apportionment tool to estimate the contributions of respective emission sources (Wu et al. 2013), that is, adding reactive tracers into the CAMx model to apportion $\mathrm{PM}_{2.5}$ components from different sub-regions and source categories. Consequently, the source information of each selected species on each grid at each time step is delivered and developed ( $\mathrm{Li}$ et al. 2015). The physical parameter schemes of the WRF and CAMx models for the air quantity simulation in this study were selected as follows: (a) twoway interactive grid nesting, (b) 12 vertical layers, and (c) gas-phase chemistry using the Carbon Bond-V mechanism, which includes 156 reactions formulations, and aerosol chemistry using the AER06 aerosol mechanism. Additional details of the CAMx model and PSAT algorithms can be found in the manual of the CAMx model.

A double nesting simulation domain was designed in this study for the integrated CAMx modelling system, as shown in Fig. 1. Domain 1 (D1) refers to the outside domain with a grid resolution of $27 \mathrm{~km} \times 27 \mathrm{~km}$. This domain covers the BTH region and surrounding provinces, including Shandong, Shanxi, most of Inner Mongolia, Liaoning, Shaanxi, Henan, Jiangsu, and parts of Jilin, Anhui, Hubei, with a total area of almost 1.8 million $\mathrm{km}^{2}$. This design includes all possible external $\mathrm{PM}_{2.5}$ emission sources (which might affect the $\mathrm{PM}_{2.5}$ concentration in the BTH region) in the simulation emission inventory. Domain 2 (D2) refers to the inside domain with a grid size of $9 \mathrm{~km} \times 9 \mathrm{~km}$, covering mainly the BTH region. D2 presumably provides an effective $\mathrm{PM}_{2.5}$ simulation resolution.

In the air quality simulation, the simulation domain must be divided into a series of sub-areas to evaluate the pollutant transport between geographic boundaries of subareas labelled by the CAMx model. Fourteen sub-areas that delineated within the D2 domain represent the 14 pollution emission source inputs to the CAMx model, as indicated in Fig. 2. The 14 sub-areas are as follows: Beijing (BJ), Tianjin (TJ), Zhangjiakou (ZJK), Chengde (CD), Qinhuangdao (QHD), Tangshan (TS), Baoding (BD), Langfang (LF), Cangzhou (CZ), Shijiazhuang (SJZ), Hengshui (HS), Xingtai (XT), Handan (HD), and other regions (OT). The receptor points close to the state-controlled monitoring stations in each sub-area were selected to simulate the $\mathrm{PM}_{2.5}$ concentrations and emission contributions from the iron and steel industry and verify the CAMx model. In addition, the simulation results for each grid point in the $\mathrm{D} 2$ domain were 


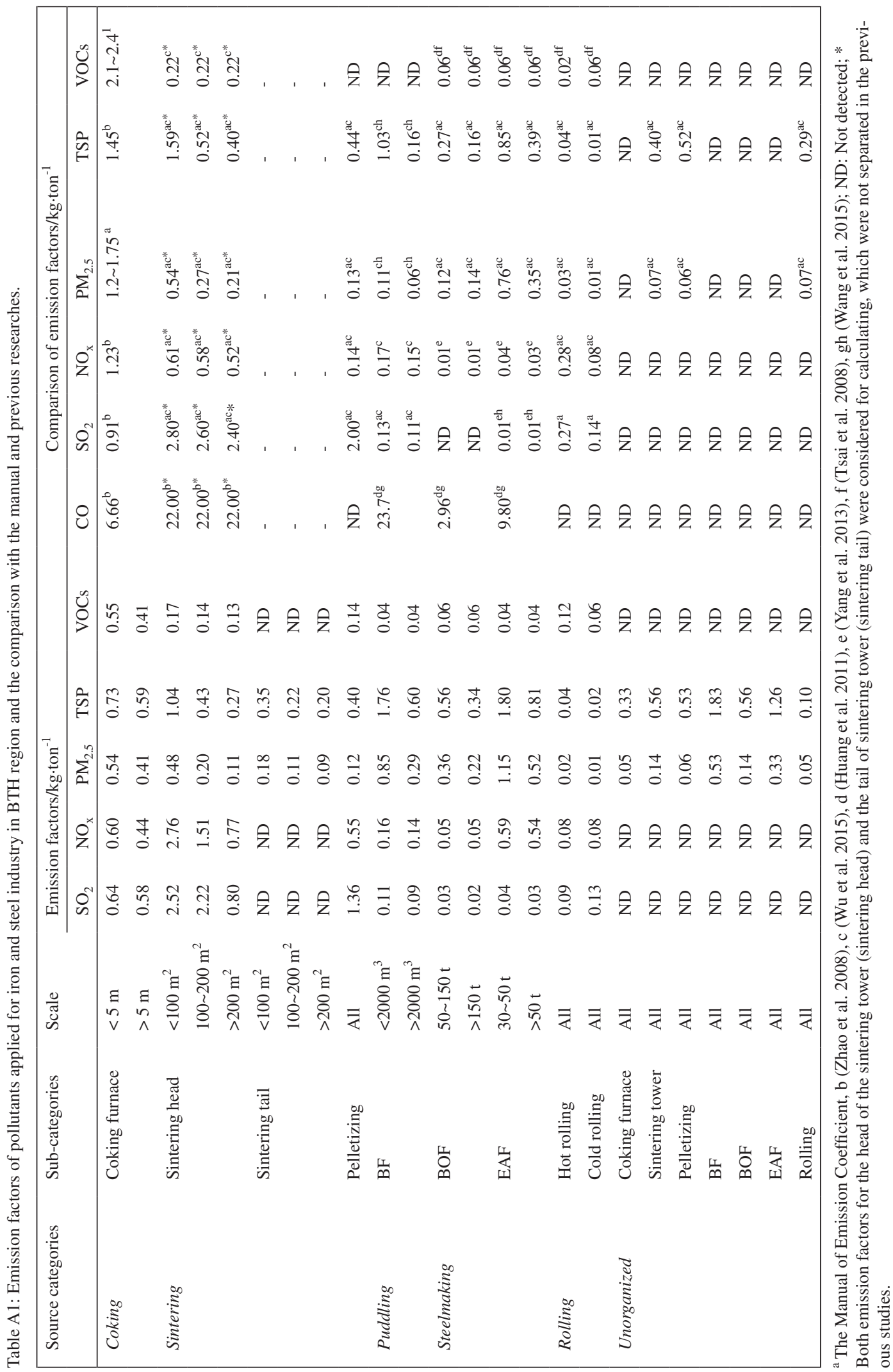


extracted, and their average values were used to investigate the influence of pollutant emissions from iron and steel enterprises on the atmospheric environment of the entire BTH region and calculate the sensitivity and classification coefficients for each enterprise.

\section{Model Verification}

The simulated $\mathrm{PM}_{2.5}$ concentrations were compared in this study with the observed data to validate the model. The indicators for model verification include correlation coefficient $(R)$, normalized mean bias $(N M B)$, normalized mean error $(N M E)$, and the fraction $\left(M_{i} / O_{i}\right)$ satisfying the condition 0.5

$M_{i} / O_{i} \quad 2$ (FAC), where $M_{i}$ and $O_{i}$ are the simulated and observed $\mathrm{PM}_{2.5}$ concentrations at time I, respectively. The statistic approaches used in this study can be found in many previous literature works (Gao et al. 2015, Wang et al. 2014, Zhang et al. 2013). Fig. 3 presents the comparison results of the simulated and observed $\mathrm{PM}_{2.5}$ mean daily concentrations in January, April, July, and October (respectively representing winter, spring, summer and autumn) of 2015 in typical sub-areas (BJ and SJZ were selected because of geographical location, TS and HD were selected because of the large number of iron and steel plant enterprises). The results indicate that high correlations between observed and simulated concentrations are obtained, with the simulation errors at an acceptable level. In particular, the values of $R$ are larger than 0.65 , with the $N M B$ ranging from $14 \%$ to $26 \%$, the $N M E$ ranges being $26 \%-49 \%$, and the $F A C$ ranges being $86 \%-126 \%$.
The model validation errors come possibly from two sources: (1) uncertainties of the emission inventory; (2) errors from the WRF-CAMx modeling process itself. However, the comparison results generally indicate that an acceptable consistency between the simulated and observed concentrations has been achieved (Dong et al. 2013, Wang et al. 2010), and the WRF-CAMx modeling system can be utilized for simulation in this study.

\section{Classification Technology Method}

The developed classification technology method is not only used for classifying the enterprises through calculating the effects of pollutant emission from enterprises on the atmospheric environment but also applied for locating the priority control of atmospheric pollution sources for regional air quality management. The classification coefficients were calculated based on sensitivity and potential coefficients. $\mathrm{CO}$ was not analysed in this section due to its minimal influence on $\mathrm{PM}_{2.5}$ concentrations (Streets et al. 2006). The detailed algorithms are presented below.

The sensitivity coefficient was selected to reflect the difference of air pollutant emissions from diverse sources on the atmospheric environment of the BTH region, which involve various influencing factors, such as spatial distance, meteorological condition, and topography condition.

$$
S I_{i}=\sum_{j} \frac{S F_{i, j}}{S_{j}}=\sum_{j} \frac{C_{i, j} / Q_{i, j}}{S_{j}}
$$
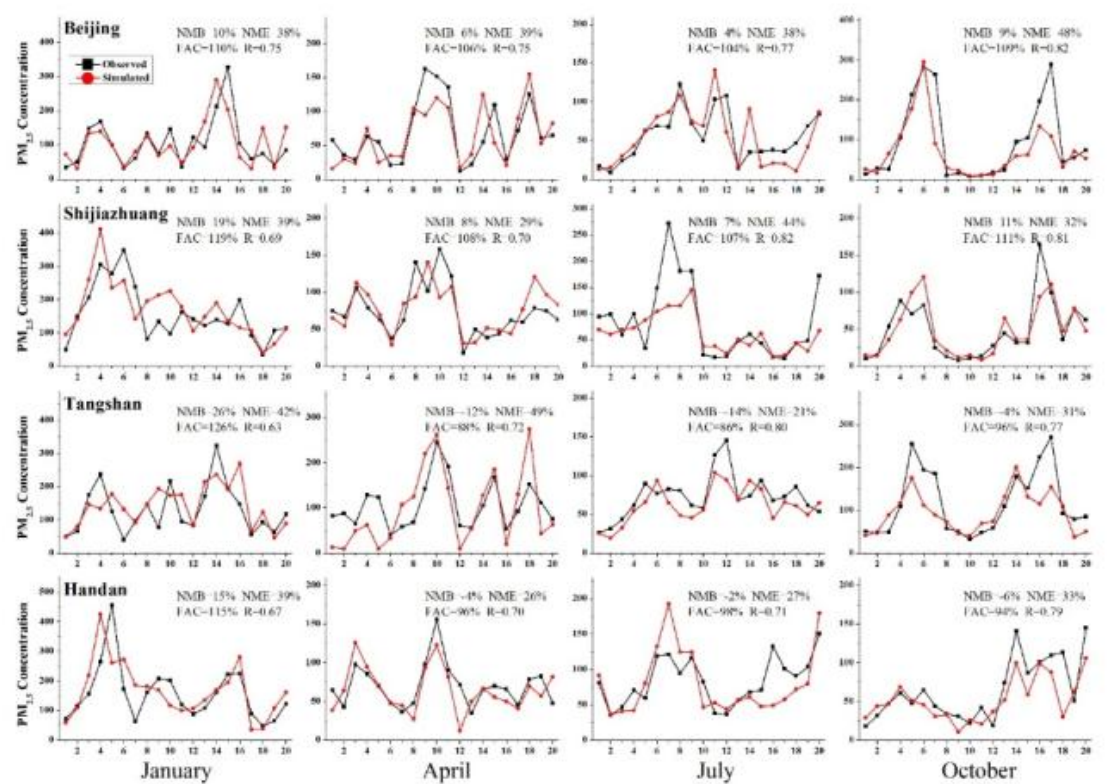

Fig. 3: Comparisons of the simulated and observed mean daily $\mathrm{PM}_{2.5}$ concentrations in 2015 for typical sub-areas. 
where $S I_{i}$ represents the sensitivity coefficient for iron and steel enterprise $i ; i$ represents emission sources, that is, the iron and steel enterprises in the BTH region; $j$ represents gaseous pollutants, namely $\mathrm{SO}_{2}, \mathrm{NO}_{\mathrm{x}}, \mathrm{PM}_{2.5}$, and VOCs; $S F_{i, j}$ represents the sensitivity coefficient of pollutant $\mathrm{j}$ from enterprise $I$ and the unit contribution concentration of the emission of pollutant $j$ from enterprise $i$ on the receptor sites, which was calculated based on simulation results; $C_{i, j}$ represents the emission contribution concentration of pollutant $j$ from enterprise $i$ on the receptor sites; $Q_{i, j}$ represents the emission amount of pollutant $j$ from enterprise $i ; S_{j}$ is the national secondary standards of China for pollutants $j$.

Potential coefficients were selected to compare the control potential of air pollutant emissions of each enterprise.

$$
P I_{i}=\sum_{j} \frac{P_{i, j}}{S_{j}}=\sum_{j} \frac{Q_{i, j} \times\left(R_{o, j}-R_{i, j}\right)}{S_{j}}
$$

where $P I_{i}$ represents the potential coefficient of iron and steel enterprise $i ; P_{i, j}$ represents the potential for emission control of pollutant $j$ in enterprise $i ; R_{o, j}$ represents the removal efficiency of pollutant $j$ by the most optimal control facilities; $R_{i, j}$ represents the removal efficiency of pollutant $j$ by the actual control facilities in enterprise $i$. The potential coefficients of VOCs for each enterprise were assumed as the same due to the lack of statistical data on VOC control facilities.

A comprehensive indicator, which is called classification coefficient, was developed on the basis of calculation of sensitivity and potential coefficients to classify the enterprises.

$$
C I_{i}=k_{1} \times S I_{i}+k_{2} \times P I_{i}
$$

where $C I_{i}$ represents the classification coefficient for iron and steel enterprise $i, k_{l}$ and $k_{2}$ represent the weight coefficients of $S I_{i}$ and $P I_{i}$, respectively, and the sum of $k_{1}$ and $k_{2}$ is equal to 1 . The authors deemed that the weight coefficient of $P I_{i}$ should be close to $S I_{i}$. Thus, $k_{l}$ and $k_{2}$ are assigned to 0.5 and 0.5 , respectively. After normalization processing, the ranges of $0.80-1.00,0.60-0.80,0.40-0.60,0.20-0.40$, and $0.00-0.20$ for classification coefficients respectively represent the first, second, third, fourth and fifth-level pollution, and these coefficients are arranged as the sequence from "most serious" to "least serious."

\section{RESULTS AND ANALYSIS}

\section{Emission Characteristics of Gaseous Pollutants and PM From Iron and Steel Enterprises}

Fig. 4 shows the pollutant emission amount of the iron and steel enterprises and the contributions of different sub-categories in the sub-areas of the BTH region (BJ was not included due to the absence of iron and steel plant enterprises). Remarkable amounts of air pollutants emitted from iron and steel enterprises were also observed. The iron and steel industry is one of the most important sources of air pollutants in the BTH region, accounting for $23.7 \%$ of $\mathrm{SO}_{2}$, $10.6 \%$ of $\mathrm{NO}_{\mathrm{x}}, 11.7 \%$ of TSP, $34.1 \%$ of $\mathrm{CO}$ and $7.5 \%$ of VOCs, which were emitted from iron and steel enterprises. Especially in TS, iron and steel enterprises contributed

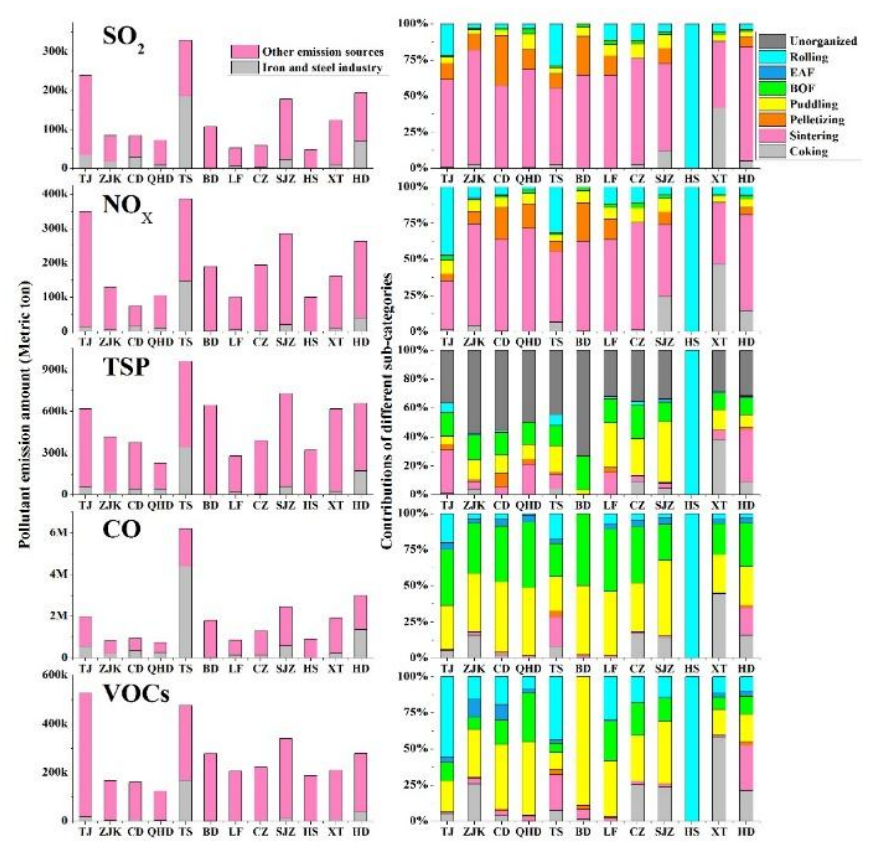

Fig. 4: Pollutant emission amount of iron and steel enterprises and contributions of different sub-categories in the BTH. 
$56.3 \%, 38.2 \%, 35.7 \%, 71.1 \%$, and $35.4 \%$ of $\mathrm{SO}_{2}, \mathrm{NO}_{\mathrm{x}}$, TSP, $\mathrm{CO}$, and VOCs, respectively, thereby illustrating that the iron and steel industry is the most important air pollution source in that area. In other sub-areas, such as HD, TJ, CD, and SJZ, a considerable amount of air pollutants were similarly emitted from the iron and steel enterprises. Thus, the iron and steel enterprises should be regarded as the main governance object to improve the quality of the atmospheric environment.

Among all the sub-categories, sintering was the most important contributor of $\mathrm{SO}_{2}$ and $\mathrm{NO}_{\mathrm{x}}$ in most sub-areas, which is consistent with the previous studies ( $\mathrm{Li}$ et al. 2016). The vast contribution was mainly in connection with limited desulfurization and denitration efficiency in the BTH region, with XT and HS as two exceptions; the former largely emits $\mathrm{SO}_{2}$ and $\mathrm{NO}_{\mathrm{x}}$ in the coking process, and the latter only includes the rolling process. For TSP, unorganized particulate matters (summation of unorganized PM from each process) escaped from each manufacturing process of sub-categories with no pollution treatment measures and accounted for approximately $38.2 \%$ of TSP in a total of the BTH. This finding indicates considerable potential for TSP pollutant control in iron and steel enterprises, and the unorganized PM should be highlighted. Moreover, the contributions of sub-categories substantially varied between sub-areas. For example, TSP from sintering towers accounted for more than $25.0 \%$ in $\mathrm{TJ}$ and $\mathrm{HD}$, whereas BOF and puddling provided additional contributions in $\mathrm{BD}$ and SJZ. CO pollutants were emitted in most sub-areas during the puddling and steelmaking processes in iron and steel enterprises, and the coking furnace was a contributor in XT, ZJK, and HD. Notably, although the emission factors of $\mathrm{CO}$ for $\mathrm{EAF}$ were higher than those of BOF, the widespread application of BOF led to a high contribution rate of $\mathrm{CO}$ emission in the $\mathrm{BTH}$ region. The CO pollutant was not discussed below due to the lack of statistical data and its minimal impact on the $\mathrm{PM}_{2.5}$ concentration. Considering the complexity of the rolling process, various procedures were involved in the process to produce and improve the number of steel productions, and most of the VOCs in HS, TJ, and TS were discharged during this process. The puddling process contributed most of the VOCs from the iron and steel industry in BD, QHD, LZ, SJZ, and $\mathrm{CD}$, and the coking process contributed most in XT and CZ.

\section{Impact of Pollutant Emission from Iron and Steel Enterprises on Atmospheric Environment}

$\mathrm{SO}_{2}, \mathrm{NO}_{\mathrm{x}}$, VOCs, and TSP are emitted from various sources. Therefore, the concentrations of $\mathrm{SO}_{4}{ }^{2-}, \mathrm{NO}_{3}{ }^{-}$, $\mathrm{SOA}$ (second organic aerosol), and $\mathrm{PM}_{2.5}$ in each sub-area were simulated from the iron and steel industry and other emission sources (such as other industrial, transportation, coal-burning, and dust sources). The unorganized $\mathrm{PM}_{2.5}$ was distributed into coking, sintering, puddling, steelmaking, and rolling processes to compare the emission contribution from each process. Thus, the emission categories of the iron and steel industry were coking, sintering, puddling, steelmaking, and rolling. Fig. 5 shows the average emission contribution of $\mathrm{PM}_{2.5}, \mathrm{SO}_{4}{ }^{2-}, \mathrm{NO}_{3}{ }^{-}$, and $\mathrm{SOA}$ in the sub-areas from each process of the iron and steel industry and other emission sources in 2015.

The iron and steel industry is one of the most important
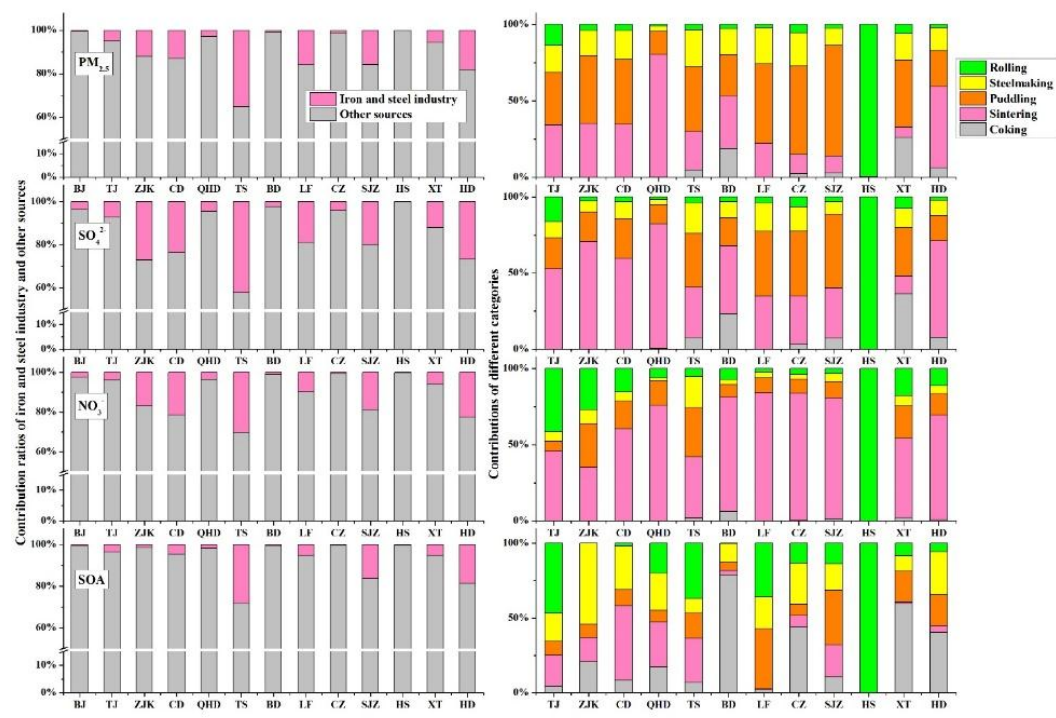

Fig. 5: Average emission contribution to $\mathrm{PM}_{2.5}, \mathrm{SO}_{4}{ }^{2-}, \mathrm{NO}_{3}{ }^{-}$, and $\mathrm{SOA}$ in the sub-areas from each process of the iron and steel industry and other emission sources in 2015 . 
pollution sources in the BTH region, especially in TS and $\mathrm{HD}$, which significantly contributed to $\mathrm{PM}_{2.5}, \mathrm{SO}_{4}{ }^{2-}, \mathrm{NO}_{3}{ }^{-}$ and SOA concentrations in the atmospheric environment in most of the sub-areas. The pollution contribution percentages of the iron and steel industry on $\mathrm{PM}_{2.5}, \mathrm{SO}_{4}{ }^{2-}, \mathrm{NO}_{3}{ }^{-}$and SOA concentrations in TS were $31.0 \%, 42.3 \%, 30.2 \%$ and $28.1 \%$, respectively. These concentrations were lower than the amount ratios of air pollutant emissions because most of the iron and steel enterprises were planted in suburbs, whereas the receptors of each sub-area were selected close to the state-controlled monitoring stations in urban areas. Overall, the atmospheric environment in most sub-areas of the BTH region was significantly influenced by the pollutant emissions of iron and steel enterprises.

As illustrated in Fig. 5, sintering and puddling contributed the majority of $\mathrm{PM}_{2.5}, \mathrm{SO}_{4}{ }^{2-}$ and $\mathrm{NO}_{3}{ }^{-}$emissions from the iron and steel industry in most sub-areas. For instance, sintering accounted for more than $50 \%$ of $\mathrm{PM}_{2.5}, \mathrm{SO}_{4}{ }^{2-}$ and $\mathrm{NO}_{3}{ }^{-}$emissions in HD and QHD, and nearly a half of $\mathrm{PM}_{2.5}$ and $\mathrm{SO}_{4}{ }^{2-}$ from the iron and steel industry were emitted from the puddling process in SJZ, CZ and LF. The puddling process contributed more $\mathrm{PM}_{2.5}$ emissions than sintering in TS, which was inconsistent with the structure of pollutant emissions. This finding is mainly due to the substantially higher chimneys in the sintering process than those in other processes, which was conducive to the diffusion and attenuation of pollutants emitted from sintering towers. Notably, although puddling and steelmaking processes were not the most significant sources of $\mathrm{SO}_{2}$ emission, their contributions for $\mathrm{SO}_{4}{ }^{2-}$ concentration should also be regarded, and the desulfurization facilities should also be established for these processes. The simulation results of SOA were taken for a preliminary investigation to determine the contribution of different categories on SOA concentration. The VOC emission of the coking process in $\mathrm{BD}, \mathrm{XT}$, and HD contributed more than $40 \%$ of SOA concentration from the iron and steel industry in the atmospheric environment, while sintering provided additional contributions to CD. Puddling also remarkably contributed to LF, and the rolling process responded in TJ and TS. This complicated situation is not only limited by the applied modelling system but also influenced by the variant characteristics and species of VOCs emitted from each category of iron and steel enterprises.

\section{Sensitivity Coefficients of Iron and Steel Enterprises}

Fig. 6 shows the sensitivity coefficients of PPM (primary fine particulate matters, the components of $\mathrm{PM}_{2.5}$ with no secondary reactions in the atmospheric environment, mainly including the primary organic compounds, elemental carbon, and crustal fine particles) (TSP-PPM), $\mathrm{SO}_{4}{ }^{2-}\left(\mathrm{SO}_{2}-\mathrm{SO}_{4}{ }^{2-}\right)$, $\mathrm{NO}_{3}{ }^{-}\left(\mathrm{NO}_{\mathrm{x}}-\mathrm{NO}_{3}{ }^{-}\right)$, and SOA (VOCs-SOA) for the iron and steel enterprises in sub-areas. The maximum value of sensitivity coefficients of different processes was regarded in this study as the sensitivity coefficient of the enterprise, which was calculated on the basis of simulation results of the emission contribution of PPM, $\mathrm{SO}_{4}{ }^{2-}, \mathrm{NO}_{3}{ }^{-}$and SOA concentrations and the amount of TSP, $\mathrm{SO}_{2}, \mathrm{NO}_{\mathrm{x}}$ and VOC pollutant emission from each enterprise in sub-areas. The sensitivity coefficients were applied to reflect the unit concentration of emission contribution from the enterprises on the atmospheric environment of the entire BTH region. A high sensitivity coefficient corresponds to a high concentration contribution of unit pollutant emission on the atmospheric environment.

Among the sub-areas, the sensitivity coefficients of iron and steel enterprises in BD, LF and SJZ were significantly larger than those of other sub-areas mainly due to geographical and meteorological factors. Considering the geography factor, these cities are located in the centre of the BTH region, resulting in the possible spread of their pollutants to the surrounding areas. Considering the meteorology factor, the regional meteorological condition in the BTH region was identified as stationary states in most circumstances (Li et al. 2015), which encouraged the diffusion of contaminants from the central sub-areas. Moreover, the special climate of the sea-land breeze (Wu et al. 2016) led to the large sensitivity coefficients of enterprises in TJ. Although TS and HD are the cities with numerous iron and steel enterprises, their sensitivity coefficients were relatively low. This finding was mainly caused by two reasons: on the one hand, the sensitivity coefficients were calculated for each enterprise rather than the summation of enterprises; on the other hand, the cities of TS and HD are located at the edge of the BTH region. By contrast, QHD had the smallest sensitivity coefficient compared with other sub-areas. Thus, QHD is a suitable destination for migrating the iron and steel enterprises from other sub-areas to realize the optimal disposition of the regional industry.

The comparison between sensitivity coefficients of different pollutants showed that the TSP emissions had a significantly higher contribution concentration of PPM than $\mathrm{SO}_{2}, \mathrm{NO}_{\mathrm{x}}$ and VOCs on secondary components. This finding was mainly due to the direct contribution of fine particles in the TSP emissions to the atmospheric environment, while $\mathrm{SO}_{4}{ }^{2-}, \mathrm{NO}_{3}{ }^{-}$and $\mathrm{SOA}$ were formed through the complicated secondary chemical reactions. Besides, the sensitivity coefficients of $\mathrm{SO}_{2}-\mathrm{SO}_{4}{ }^{2-}$ were slightly larger than that of $\mathrm{NO}_{\mathrm{x}}-\mathrm{NO}_{3}{ }^{-}$in most sub-areas. This result is consistent with the chemical generating mechanisms, in which the generation of $\mathrm{NO}_{3}{ }^{-}$from $\mathrm{NO}_{\mathrm{x}}$ is complicated (Dong et al. 2013) and vulnerable to the neighbouring environment. The relatively low sensitivity coefficients of VOCs-SOA were mainly caused by the limitation of the CAMx model (Bossioli et al. 2013). 


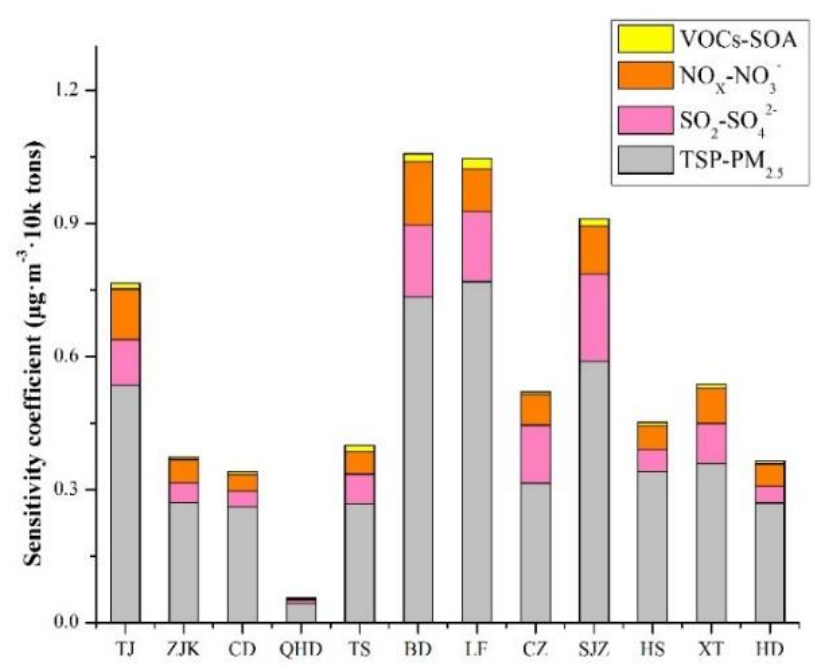

Fig. 6: Sensitivity coefficients of $\mathrm{PPM}, \mathrm{SO}_{4}{ }^{2-}, \mathrm{NO}_{3}{ }^{-}$and SOA for iron and steel enterprises in the sub-areas of the $\mathrm{BTH}$ region.

Fig. 7 shows the wind rose schematic of partial sub-areas (BJ, TJ, TS, HD, ZJK, BD, LF, SJZ and XT) in the BTH region in 2015. As illustrated, the frequency of north-west wind for central sub-areas (such as $\mathrm{BJ}, \mathrm{BD}$, and $\mathrm{LF}$ ) was quite low. This finding indicates that the emission of air pollutants in northern cities was rarely transported to the central and southern sub-areas, which might be the main reason for the relatively low sensitivity coefficients of the iron and steel enterprises in northern sub-areas (such as ZJK). The frequency of static wind (the speed of wind lower than $1 \mathrm{~m} / \mathrm{s}$ ) for central sub-areas was relatively high, and the static and stable climate promoted the steady spread of the air pollutants from central sub-areas to the surrounding areas, resulting in the high sensitivity coefficients of iron and steel enterprises in central sub-areas. Transporting the air pollutants of southern sub-areas (such as HD and XT), whose locations are relatively remote in the BTH region, to other sub-areas, was difficult.

\section{Classification Result of Iron and Steel Enterprises}

The classification coefficients of iron and steel enterprises in the BTH region were calculated on the basis of sensitivity and potential coefficients for each process of enterprises, and each kind of pollutant $\left(\mathrm{PM}_{2.5}, \mathrm{SO}_{2}, \mathrm{NO}_{\mathrm{x}}\right.$, and VOCs) was considered. The maximum value of the classification coefficients of different processes was regarded in this study as the classification coefficient of the enterprise due to the difference in the number of processes of each iron and steel enterprise. For example, some enterprises were equipped with the entire processes of coking, sintering, puddling, steelmaking, and rolling, while others were likely to comprise

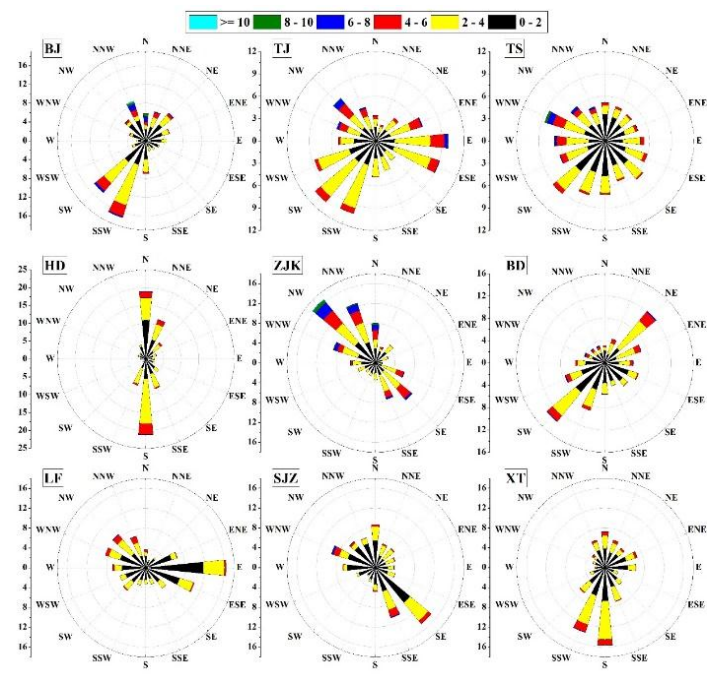

Fig. 7: Wind rose schematic of some sub-areas in the BTH region in 2015 .

only one or two processes. The classification coefficients were calculated for each iron and steel enterprise. Therefore, the Kriging interpolation method built into the Geographic Information System was used as a spatial interpolation technique to analyze the distribution of classification results. Fig. 8 shows the classification results of each iron and steel enterprise in the BTH region.

The distributions of classification coefficients of iron and steel enterprises in the BTH region indicate that the

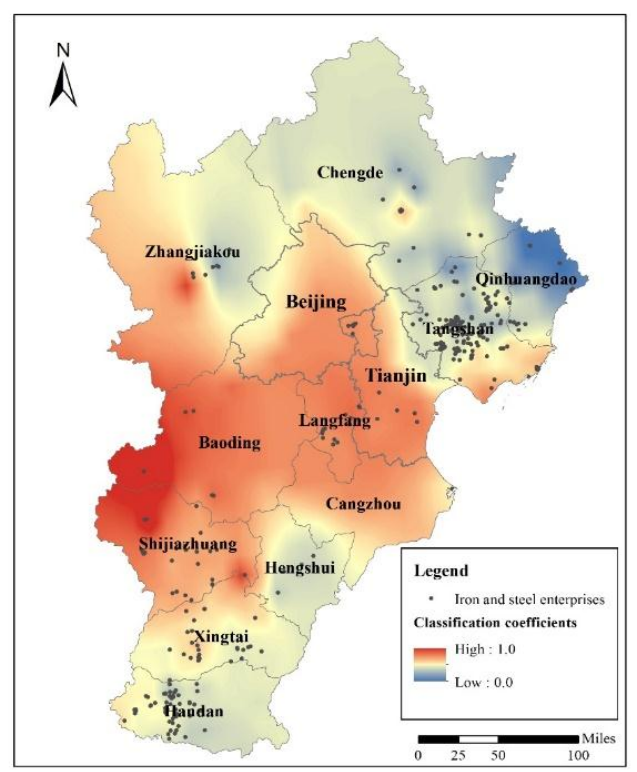

Fig. 8: Classification results of each iron and steel enterprise in the BTH region. 
enterprises in western sub-areas, such as $\mathrm{BD}, \mathrm{SJZ}$ and ZJK, had higher classification coefficients than those in eastern sub-areas, such as HS, TS, and QHD. On the one hand, the northwest wind was one of the dominant wind directions in the BTH region (Zhao et al. 2008). On the other hand, the western and eastern of the BTH region are dominated by plateau and plain, respectively. These findings prompted pollutant diffusion from west to east and prevented the diffusion from east to west. Moreover, the topographic features explain the difference between the classification coefficients of enterprises in sub-areas. In addition, the enterprises in central sub-regions had higher classification coefficients than those of other sub-areas considering the stationary atmospheric conditions, which frequently occurred in the $\mathrm{BTH}$ region and favoured pollutant diffusion from central sub-areas to surrounding areas.

As illustrated in Fig. 8, parts of the classification coefficients for enterprises in BD, SJZ and LF were higher than 0.80 , which were classified as the first-level pollution known as "Most Serious." These enterprises had the largest classification coefficients in the BTH region, which is consistent with their high emission sensitivity and control potential. Therefore, these enterprises should be preferentially considered when the iron and steel enterprises in the BTH region were demanded to close down for resolving the overcapacity and improving the quality of the atmospheric environment. Notably, the sensitivity coefficients of enterprises in ZJK were smaller than those of XT and CZ (Fig. 6), while their classification coefficients were nearly the same, even high for some enterprises in ZJK. This finding was mainly due to the high potential coefficients of the enterprises in $\mathrm{ZJK}$, and these enterprises should also be highlighted. Among the sub-areas, the classification coefficients of enterprises in QHD were the smallest and classified as the fifth-level pollution, namely, "Least Serious." This finding illustrates that their pollutants emission contributed fewer negative effects on the atmospheric environment in the BTH region than those of the enterprises in other sub-areas. Overall, the classification results suggested that the iron and steel enterprises in BD, LF, SJZ, and ZJK should be given the priority to control, while the enterprises in QHD should be taken into the least consideration to control the acquisition of improved air quality for the BTH region.

\section{CONCLUSION}

The iron and steel industry has a strong negative impact on human health. Therefore, a detailed and high-resolution emission inventory of the iron and steel industry in the BTH region was built with detailed activity information based on the emission factors calculated for each sub-category of iron and steel enterprises.

The CAMx modelling system was implemented to investigate the influence of pollution emission from sources on $\mathrm{PM}_{2.5}$ concentration and simulate the emission sensitivity of enterprises to various pollutants. A classification technology method was then developed and applied to classify the iron and steel enterprises in the $\mathrm{BTH}$ region considering the sensitivity results and emissions control potential. Moreover, simulation scenarios were assumed and simulated to assess the influence of reducing the pollutant emissions of the iron and steel industry quantitatively.

As calculated in the inventory, the iron and steel industry is one of the most important pollutant sources in the BTH region, and the CAMx simulation results showed that the atmospheric environment in most sub-areas was significantly influenced by the pollutant emission of iron and steel enterprises. Therefore, the iron and steel enterprises in western and central sub-areas were classified to have higher classification coefficients than other sub-areas, providing a sequence of rectifying enterprises. The results obtained from this study can help make sound control policies and measures to reduce the negative impact of air pollution on human health.

\section{ACKNOWLEDGMENT}

This study was funded by the Science and Technology Planning Project of Henan Province in China (No. 192102310009).

\section{REFERENCES}

Amodio, M., Andriani, E., De Gennaro, G., Di Gilio, A., Ielpo, P., Placentino, C.M. and Tutino, M. 2013. How a steel plant affects air quality of a nearby urban area: a study on metals and PAH concentrations. Aerosol and Air Quality Research, 13: 497-508.

Bossioli, E., Tombrou, M., Helmis, C., Kurtenbach, R., Wiesen, P., Schäfer, K., Dandou, A. and Varotsos, K.V. 2013. Issues related to aircraft take-off plumes in a mesoscale photochemical model. Science of the Total Environment, 456: 69-81.

Chen, Y. and Xie, S.D. 2014. Characteristics and formation mechanism of a heavy air pollution episode caused by biomass burning in Chengdu, Southwest China. Science of the Total Environment, 473: 507-517.

Cheng, S., Zhou, Y., Li, J., Lang, J. and Wang, H. 2012. A new statistical modeling and optimization framework for establishing high-resolution PM10 emission inventory-I. Stepwise regression model development and application. Atmospheric Environment, 60: 613-622.

Dong, X., Gao, Y., Fu, J.S., Li, J., Huang, K., Zhuang, G. and Zhou, Y. 2013. Probe into gaseous pollution and assessment of air quality benefit under sector dependent emission control strategies over megacities in Yangtze River Delta, China. Atmospheric Environment, 79: 841-852.

Gao, Y., Zhang, M., Liu, Z., Wang, L., Wang, P., Xia, X., Tao, M. and Zhu, L. 2015. Modeling the feedback between aerosol and meteorological variables in the atmospheric boundary layer during a severe fog-haze event over the North China Plain. Atmospheric Chemistry and Physics, 15: 4279-4295. 
Guttikunda, S.K. and Jawahar, P. 2014. Atmospheric emissions and pollution from the coal-fired thermal power plants in India. Atmospheric Environment, 92: 449-460.

Huang, C., Chen, C.H., Li, L., Cheng, Z., Wang, H.L., Huang, H.Y., Streets, D.G., Wang, Y.J., Zhang, G.F. and Chen, Y.R. 2011. Emission inventory of anthropogenic air pollutants and VOC species in the Yangtze River Delta region, China. Atmospheric Chemistry \& Physics, 11: 4105-4120.

Huang, R.J., Zhang, Y., Bozzetti, C., Ho, K.F., Cao, J.J., Han, Y., Daellenbach, K.R., Slowik, J.G., Platt, S.M., Canonaco, F. and Zotter, P. 2014. High secondary aerosol contribution to particulate pollution during haze events in China. Nature, 514: 218-222.

Jia, J., Cheng, S., Liu, L., Lang, J., Wang, G., Chen, G. and Liu, X. 2017. An integrated WRF-CAMx modeling approach for impact analysis of implementing the emergency PM2.5 control measures during red alerts in Beijing in December 2015. Aerosol \& Air Quality Research, 17: 2491-2508.

Li, G., Cheng, S., Li, J., Wei, W., Wen, W. and Wang, G. 2014. Characterization of ambient ozone and its precursors around a coking plant. Environmental Monitoring and Assessment, 186: 3165-3179.

Li, H., Wang, Q.G., Yang, M., Li, F., Wang, J., Sun, Y., Wang, C., Wu, H. and Qian, X. 2016. Chemical characterization and source apportionment of PM2.5 aerosols in a megacity of Southeast China. Atmospheric Research, 181: 288-299.

Li, L., An, J.Y., Zhou, M., Yan, R.S., Huang, C., Lu, Q., Lin, L., Wang, Y.J., Tao, S.K., Qiao, L.P. and Zhu, S.H. 2015. Source apportionment of fine particles and its chemical components over the Yangtze River Delta, China during a heavy haze pollution episode. Atmospheric Environment, 123: 415-429.

Li, W., Lu, C., Ding, Y. and Zhang, Y.W. 2017. The impacts of policy mix for resolving overcapacity in heavy chemical industry and operating national carbon emission trading market in China. Applied Energy, 204: 509-524.

Li, X., Zhang, Q., Zhang, Y., Zheng, B., Wang, K., Chen, Y., Wallington, T.J., Han, W., Shen, W., Zhang, X. and He, K. 2015. Source contributions of urban PM2.5 in the Beijing-Tianjin-Hebei region: Changes between 2006 and 2013 and relative impacts of emissions and meteorology. Atmospheric Environment, 123: 229-239.

Pateraki, S., Assimakopoulos, V.D., Maggos, T., Fameli, K.M., Kotroni, V. and Vasilakos, C. 2013. Particulate matter pollution over a Mediterranean urban area. Science of the Total Environment, 463: 508-524.

Sina, A. and Kaur, D. 2019. Load frequency control of multi area interconnected power system using differential evolution algorithm. Tehnicki Glasnik-Technical Journal, 2013: 323-330.

Streets, D.G., Bond, T.C., Carmichael, G.R., Fernandes, S.D., Fu, Q., He, D., Klimont, Z., Nelson, S.M., Tsai, N.Y., Wang, M.Q. and Woo, J.H. 2003. An inventory of gaseous and primary aerosol emissions in Asia in the year 2000. Journal of Geophysical Research Atmospheres 2003, 108, GTE 30-31.

Tang, X., Zhang, Y., Yi, H., Ma, J. and Pu, L. 2012. Development a detailed inventory framework for estimating major pollutants emissions inventory for Yunnan Province, China. Atmospheric Environment, 57: 116-125.

Tao, J., Gao, J., Zhang, L., Zhang, R., Che, H., Zhang, Z., Lin, Z., Jing, J., Cao, J. and Hsu, S.C. 2014. PM2.5 pollution in a megacity of southwest China: source apportionment and implication. Atmospheric Chemistry and Physics, 14: 8679-8699.

Tsai, J.H., Lin, K.H., Chen, C.Y., Lai, N., Ma, S.Y. and Chiang, H.L. 2008. Volatile organic compound constituents from an integrated iron and steel facility. Journal of Hazardous Materials, 157: 569-578.

Wang, G., Cheng, S., Lang, J., Yang, X., Wang, X., Chen, G., Liu, X. and Zhang, H. 2016. Characteristics of PM2.5 and assessing effects of emission-reduction measures in the heavy polluted city of Shijiazhuang, before, during, and after the Ceremonial Parade 2015. Aerosol \& Air Quality Research, 17: 499-512.

Wang, G., Cheng, S., Li, J., Lang, J., Wen, W., Yang, X. and Tian, L. 2015.
Source apportionment and seasonal variation of PM2.5 carbonaceous aerosol in the Beijing-Tianjin-Hebei region of China. Environmental Monitoring \& Assessment, 187: 143-155.

Wang, K., Tian, H., Hua, S., Zhu, C., Gao, J., Xue, Y., Hao, J., Wang, Y. and Zhou, J. 2016. A comprehensive emission inventory of multiple air pollutants from iron and steel industry in China: Temporal trends and spatial variation characteristics. Science of the Total Environment, 559: 7-14

Wang, L., Wei, Z., Wei, W., Fu, J.S., Meng, C. and Ma, S. 2015. Source apportionment of PM2.5 in top polluted cities in Hebei, China using the CMAQ model. Atmospheric Environment, 122: 723-736.

Wang, L.T., Wei, Z., Yang, J., Zhang, Y., Zhang, F.F., Su, J., Meng, C.C. and Zhang, Q. 2014. The 2013 severe haze over southern Hebei, China: model evaluation, source apportionment, and policy implications. Atmospheric Chemistry and Physics, 14: 3151-3173.

Wang, S., Zhao, M., Xing, J., Wu, Y., Zhou, Y., Lei, Y., He, K., Fu, L. and Hao, J. 2010. Quantifying the Air Pollutants Emission Reduction during the 2008 Olympic Games in Beijing. Environmental Science \& Technology, 44: 2490-2496.

Wei, W., Cheng, S., Li, G., Wang, G. and Wang, H. 2014. Characteristics of ozone and ozone precursors (VOCs and $\mathrm{NOx}$ ) around a petroleum refinery in Beijing, China. Journal of Environmental Sciences, 26: 332-342.

Wei, W., Cheng, S., Li, G., Wang, G. and Wang, H. 2014. Characteristics of volatile organic compounds (VOCs) emitted from a petroleum refinery in Beijing, China. Atmospheric Environment, 89: 358-366.

Wei, W., Lv, Z., Yang, G., Cheng, S., Li, Y. and Wang, L. 2016. VOCs emission rate estimate for complicated industrial area source using an inversedispersion calculation method: A case study on a petroleum refinery in Northern China. Environmental Pollution, 218: 681-688.

Wu, D., Fung, J.C.H., Yao, T. and Lau, A.K.H. 2013. A study of control policy in the Pearl River Delta region by using the particulate matter source apportionment method. Atmospheric Environment, 76: 147-161.

Wu, M., Luo, Y., Wu, D. and Fan, S. 2016. Observation on the characteristics of sea-land breezes and its influence to air quality over Pearl River Delta region during dry season. China Environmental Science, 36: 3263-3272.

Wu, X., Zhao, L., Zhang, Y., Zheng, C., Gao, X. and Cen, K. 2015. Primary air pollutant emissions and future prediction of iron and steel industry in China. Aerosol and Air Quality Research, 15: 1422-1432.

Yang, J., Ma, S., Gao, B., Li, X., Zhang, Y., Cai, J., Li, M., Huang, B. and Zheng, M. 2017. Single particle mass spectral signatures from vehicle exhaust particles and the source apportionment of on-line PM2.5 by single particle aerosol mass spectrometry. Science of the Total Environment, 593: 310-318

Yang, X., Zhang, L. and Jiang, D. 2013. Exhaust gas of iron \& steel industry and emission characteristics of pm2.5 and pollution control measures. Journal of Engineering Studies, 5: 240-251.

Zhang, Y. and Wu, S.Y.. 2013. Fine scale modeling of agricultural air quality over the southeastern united states using two air quality models. Part II. Sensitivity studies and policy implications. Aerosol and Air Quality Research, 13: 1475-1491.

Zhao, B. and Ma, J.Z. 2008. Development of an air pollutant emission inventory for Tianjin. Acta Scientiae Circumstantiae, 28: 368-375.

Zhao, B., Wang, P., Ma, J.Z., Zhu, S., Pozzer, A. and Li, W.J.A.C. 2012. A high-resolution emission inventory of primary pollutants for the Huabei region, China. Atmospheric Chemistry \& Physics, 11: 20331-20374.

Zheng, J., Zhang, L., Che, W., Zheng, Z. and Yin, S. 2009. A highly resolved temporal and spatial air pollutant emission inventory for the Pearl River Delta region, China and its uncertainty assessment. Atmospheric Environment, 43: 5112-5122.

Zhou, Y., Cheng, S., Chen, D., Lang, J., Zhao, B. and Wei, W. 2014. A new statistical approach for establishing high-resolution emission inventory of primary gaseous air pollutants. Atmospheric Environment, 94: 392-401. 